\title{
Human insulin - is there still a place for it in everyday practice?
}

\begin{abstract}
Type 2 diabetes is a progressive disease where in case of unsuccessful behavioral modifications and metformin monotherapy treatment needs to be intensified by adding some other oral agents and/or GLP-1 agonists and/ /or basal insulin. After some years of treatment with increasing defect of beta cells, there is a necessity to start or intensify insulin therapy with prandial insulin, premixed insulin, basal-bolus regimen or multiple injections of insulin. Patient's treatment should be individualized but there are no direct recommendations which type of insulin to choose - human or analogue one. This article summarizes clinical situations in which one could consider using human insulin. When selecting a suitable insulin, the type of dietary habits, especially eating snacks, the presence of gastroparesis and economic issues should be taken into account. It turnes out that for patients with type 2 diabetes both human and analogue insulins are equally safe and efficient in terms of risk of severe hypoglycaemia. Undoubtedly, analogue insulin has uncontestable advantages, but in some clinical cases human insulin seems to be a better option. (Clin Diabetol 2018; 7, 3: 171-174)
\end{abstract}

Key words: diabetes mellitus, human insulin, analogue insulin

\footnotetext{
Address for correspondence: dr n. med. Katarzyna Nabrdalik Katedra i Klinika Chorób Wewnętrznych, Diabetologii i Nefrologii Śląski Uniwersytet Medyczny

Wydział Lekarskie z Oddziałem Lekarsko-Dentystycznym w Zabrzu e-mail: knabrdalik@yahoo.com

Translation: lek. Jędrzej Toczko

Clinical Diabetology 2018, 7, 3, 171-174

DOI: $10.5603 /$ DK.2018.0014
}

Received: 16.04.2018

Accepted: 18.04.2018

\section{Introduction}

The number of patients with type 2 diabetes, a disease named the non-infectious epidemic of the 21-st century, continues to increase year over year. With each issue, the periodic reports by the IDF - International Diabetes Federation - convey worsening statistical data concerning the prevalence of diabetes worldwide. Up to date statistics show that the number of diabetic patients will increase from 425 million in the year 2017 to 629 million in the year 2045 [1]. Due to a progress in antidiabetic medications used, as well as multimodal treatment of diabetic patients, the average life expectancy of a diabetic patient has increased. Consequently, both duration of the disease and the time in which the individual, target values of glycaemia need to be maintained, have also grown. In case of unsuccessful behavioral modifications and metformin monotherapy, there is a need to intensify the treatment by adding some other oral agents and/or GLP-1 agonists and/or basal insulin. After some years of treatment with increasing defect of beta cells, there is a necessity to start prandial insulin therapy as premixed insulin, basal-bolus regimen or multiple injections [2, 3]. Since the first use of insulin in 1922, a steady progress in pharmacokinetics and pharmacodynamics of insulin medications has been observed. We have classical human insulins, insulin analogues and biosimilar insulins at our disposal, differing in onset, peak and duration of action, as well as the therapy cost. Nevertheless, many patients still fail to reach target glycemic values [4]. This motivates further efforts to develop newer insulin medications, in order to improve glycaemic control and reach the physiological ideal insulin action [5]. In a view of the constantly increasing number of diabetic patients, those who use insulin among them, as well as the individual and social costs of therapy, a question 
must be asked - what criteria should be applied in choosing the insulin for a type 2 diabetic patient [6-8]?

\section{Human or analogue insulin?}

Both polish and international diabetic associations agree that the treatment of diabetes should be, above all, individualized [6, 7] and not only efficient, but also safe and without negative effect on the patient's quality of life [8]. It is recommended for type 2 diabetic patients to maintain target values of $\mathrm{HbA}_{1 \mathrm{c}}$ below or equal to $7 \%$. However, these recommendations do not state which kind of insulin - human or analogue - should be used, leaving the choice to the physician, in accordance with patient's individual needs and preferences. While choosing the therapy, one should consider the patient's lifestyle and alimentary habits regarding the quality and frequency of meals, the risks and occurrence of hypoglycemic episodes, as well as the cost of the treatment. In case of type 2 diabetic patients, research comparing prandial insulin analogues and human insulins does not show an unambiguous difference in reaching better glycaemic control or reducing the risk of hypoglycemic episodes between the discussed treatment modalities. The advantages of rapid acting analogue insulin are the possibility of using it during or even after the meal, the chance to reduce the number of meals or snacks, lower increase in body mass and less episodes of hypoglycemia in the late postprandial period or during the night [9].

In comparison to NPH insulin, the long lasting analogue insulin has been proved to reduce the risk of occurrence of any hypoglycemia and nighttime hypoglycemia. Additional benefits are the option to treat with a single injection only and a peak-less hypoglycemic effect, combined with low absorption variability in individual patients, as well as between different patients $[9,10]$.

Insulin therapy in type 2 diabetes is most frequently initiated with basal insulin - ispophane NPH or a long-acting insulin analogue - administered once a day [6]. In Poland, long-acting insulin analogues are reimbursed for type 2 diabetic patients only after a 6-month period of treatment with insulin NPH and having met specific reimbursement criteria [11]. However, there is a large group of patients who cannot afford the cost of an long-acting insulin analogue therapy, despite having met the criteria for reimbursement. For these patients, NPH insulin is the only acceptable therapeutic option [12].

The introduction of premixed insulin, basal-bolus scheme or even multiple injections of insulin may be considered when basal insulin is used in the dose exceeding $30 \mathrm{IU}$ a day with poor metabolic control, or when introduction of insulin treatment was postponed and resulted in a significant hyperglycemia with $\mathrm{HbA}_{1 \mathrm{c}}$ levels exceeding the therapeutic goals [6]. A variety of premixed human insulin preparations with different proportions of rapid-acting and long-acting insulin are available in Poland. This gives the opportunity to flexible selection of the appropriate insulin with a wider therapeutic options comparing to insulin analogues.

Aside from the basal-plus or basal-bolus regimens of insulin therapy, the premixed insulin regimen may be a next step in intensifying insulin therapy, when basal insulin therapy becomes insufficient [8]. Both human and analogue premixed insulin contain a fixed ratio of short/rapid acting to long-acting insulin what on one hand provides prandial and basal insulin in a single injection but on the other hand reduces the unlimited modifications of insulin dosage and time of administration, enforcing regularity of injections and similar quality of ingested meals [13]. For patients who are not able to give up snacks, premixed human insulin may be a more beneficial therapeutic choice because of the longer total time of action. Moreover, there is no convincing evidence for better safety or/and effectiveness of human or analogue insulin. The final choice of insulin preparation should be made individually, taking the patient's preference regarding the number of meals and therapy costs into consideration [12].

The premixed insulin therapeutic regimen is one of the most commonly used in many countries [14]. Yet, results of studies comparing the effectiveness of premixed human insulin to premixed insulin analogues have not assessed switching premixed insulin analogue therapy to human one. For this reason, we conducted a large, observational study PORGENS BENEFIT — including 3264 type 2 diabetes patients. To our knowledge, this is the first study assessing the efficiency, safety and quality of treatment satisfaction of patients using premixed insulin analogues, in comparison to patients who switched to human premixed insulin because of poor metabolic control and/or patient's preference. The outcomes of the study proved that both therapeutic options are safe and efficient, and the patients are satisfied with the applied treatment [15].

One of the clinical situations in diabetes, in which the use of human insulin over analogue insulin seems to be beneficial is diabetic autonomic neuropathy of the digestive system.

Referenced data shows that delayed gastric emptying occurs in $25-55 \%$ of type 1 diabetic patients and in approximately $30 \%$ of type 2 diabetic patients [16]. The occurrence of gastroparesis greatly hinders efficient diabetes treatment, causing the use of oral medications impossible and becomes an indication for introducing 
insulin therapy. Treatment of patients with diabetic autonomic neuropathy of the digestive system is not an easy task because food absorption is delayed and often unpredictable. In case of using insulin analogues, a postpriandal hypoglycemia may occur, followed by hyperglycemia caused by delayed absorption of nutrients and the rebound effect. Therefore, short-acting human insulin is an optimal therapeutic choice in these cases, as its pharmacokinetics and pharmacodynamics allows a better control of postprandial glycaemia [17].

Clinicians face the choice of an optimal insulin type not only in outpatients clinics, but also in emergency cases, like ketoacidosis, and in the following recovery period. In 2009 G. Umpierrez et al. conducted a multicenter, randomized study on a group of 74 patients with diabetic ketoacidosis treated with intravenous infusions of human or analogue insulin. The treatment was then continued respectively with NPH insulin combined with short acting human insulin, or with long-acting insulin analogue combined with rapidacting insulin one. No differences in doses of insulin or time necessary to treat acidosis were observed in relation to the kind of insulin used. However, it must be stated, that after the acute phase of decompensation of diabetes, the use of analogue insulin was related to lower rate of hypoglycemic episodes occurrence [18].

Furthermore, given the increasing accessibility of modern therapeutic methods such as personal insulin pumps - which are also used in some type 2 diabetes patients - we should contemplate the role of human insulin in these cases. Rapid acting insulin analogues are most commonly used in treatment with personal insulin pumps. Nonetheless, some reported cases describe the occurrence of lipoatrophy at the injection site, when analogues were administered in a continuous infusion. This pathology did not progress after switching the medication to human short acting insulin [19].

\section{Summary}

Since different types of insulin - human, analogue and biosimilar ones are available on the market - the treatment can be personalized. There are, however, some clinical situations in type 2 diabetes - in which the therapy regimen with human insulin seem to be an equal, or even a better choice. These include different lifestyle and alimentary habits, mainly snacking between main meals, and presence of gastroparesis but also - in case of long-acting insulin - economic factors, limiting its use beyond the reimbursement policy. In Poland, the financial aspect had been a common cause of treating patients - even those with type 1 diabetes - with short acting human insulin. Since the introduction of biosimilar, rapid acting insulin ana- logues, its price is comparable to the price of human insulin. However, as was mentioned above, a major difference between the cost of human and analogue basal insulin is still present.

\section{REFERENCES}

1. International Diabetes Federation. IDF Diabetes Atlas, 8th edn. Brussels, Belgium: International Diabetes Federation. http://www. diabetesatlas.org (2017).

2. Inzucchi SE, Bergenstal RM, Buse JB, et al. Management of hyperglycaemia in type 2 diabetes: a patient-centered approach. Position statement of the American Diabetes Association (ADA) and the European Association for the Study of Diabetes (EASD). Diabetologia. 2012; 55(6): 1577-1596, doi: 10.1007/s00125-0122534-0, indexed in Pubmed: 22526604.

3. Turner RC, Cull CA, Frighi V, et al. Glycemic control with diet, sulfonylurea, metformin, or insulin in patients with type 2 diabetes mellitus: progressive requirement for multiple therapies (UKPDS 49). UK Prospective Diabetes Study (UKPDS) Group. JAMA. 1999; 281(21): 2005-2012, doi: 10.1001/jama.281.21.2005, indexed in Pubmed: 10359389.

4. Levy P. The current unmet need in type 2 diabetes mellitus: addressing glycemia and cardiovascular disease. Postgrad Med. 2009; 121(3 Suppl 1): 7-12, doi: 10.3810/pgm.2009.05. suppl53.287, indexed in Pubmed: 19494472.

5. Danne T, Heinemann L, Bolinder J. New Insulins, Biosimilars, and Insulin Therapy. Diabetes Technol Ther 2018; 20: 55-70, doi: 10.1089/dia.2016.2505.

6. Polskie Towarzystwo Diabetologiczne. Zalecenia kliniczne dotyczące postępowania u chorych na cukrzycę 2018. Clinical Diabetology. 2018; 4(suppl A).

7. Standards of Medical Care in Diabetes - 2018 Introduction. Diabetes Care. 2018; 41: 1-2.

8. Inzucchi SE, Bergenstal RM, Buse JB, et al. Management of hyperglycemia in type 2 diabetes, 2015: a patient-centered approach: update to a position statement of the American Diabetes Association and the European Association for the Study of Diabetes. Diabetes Care. 2015; 38(1): 140-149, doi: 10.2337/dc14-2441, indexed in Pubmed: 25538310.

9. Siebenhofer A, Plank J, Berghold A, et al. Short acting insulin analogues versus regular human insulin in patients with diabetes mellitus. Cochrane Database Syst Rev. 2006(2): CD003287, doi: 10.1002/14651858.CD003287.pub4, indexed in Pubmed: 16625575.

10. Horvath $K$, Jeitler $K$, Berghold A, et al. Long-acting insulin analogues versus NPH insulin (human isophane insulin) for type 2 diabetes mellitus. Cochrane Database Syst Rev. 2007(2): CD005613, doi: 10.1002/14651858.CD005613.pub3, indexed in Pubmed: 17443605.

11. dziennikustaw.gov.pl/du/2018/281/D2018000028101.pdf.

12. Davidson M. Insulin Analogs - Is There a Compelling Case to Use Them? No!: Table 1. Diabetes Care. 2014; 37(6): 1771-1774, doi: 10.2337/dc13-2915.

13. Garber AJ, Ligthelm R, Christiansen JS, et al. Premixed insulin treatment for type 2 diabetes: analogue or human? Diabetes Obes Metab. 2007; 9(5): 630-639, doi: 10.1111/j.14631326.2006.00654.x, indexed in Pubmed: 17697056.

14. Kalra S, Balhara YPS, Sahay BK, et al. Why is premixed insulin the preferred insulin? Novel answers to a decade-old question. J Assoc Physicians India. 2013; 61(1 Suppl): 9-11, indexed in Pubmed: 24482980.

15. Nabrdalik K, Kwiendacz H, Sawczyn T, et al. Efficacy, Safety, and Quality of Treatment Satisfaction of Premixed Human and Analogue Insulin Regimens in a Large Cohort of Type 2 Diabetic Patients: PROGENS BENEFIT Observational Study. International Journal of Endocrinology. 2018; 2018: 1-7, doi: $10.1155 / 2018 / 6536178$. 
16. Alipour Z, Khatib F, Tabib SM, et al. Assessment of the Prevalence of Diabetic Gastroparesis and Validation of Gastric Emptying Scintigraphy for Diagnosis. Mol Imaging Radionucl Ther. 2017; 26(1): 17-23, doi: 10.4274/mirt.61587, indexed in Pubmed: 28291006.

17. Sieradzki J. Gastrointestinal neuropathy and different insulins. s.I.: Diab Clin. 2010; 11: 35-38.

18. Umpierrez GE, Jones $S$, Smiley $D$, et al. Insulin analogs versus human insulin in the treatment of patients with diabetic ke- toacidosis: a randomized controlled trial. Diabetes Care. 2009; 32(7): 1164-1169, doi: 10.2337/dc09-0169, indexed in Pubmed: 19366972.

19. Griffin ME, Feder A, Tamborlane WV. Lipoatrophy associated with lispro insulin in insulin pump therapy: an old complication, a new cause? Diabetes Care. 2001; 24(1): 174, doi: 10.2337/ /diacare.26.3.953, indexed in Pubmed: 11194227. 